\title{
LONG TERMS AND READABILITY OF PHYSICS SCHOOL TEXT
}

\author{
Ivana Škorecová, ${ }^{1}$ Aba Teleki, ${ }^{2}$ L'ubomír Zelenický ${ }^{3}$
}

\begin{abstract}
This article presents a comparison of two physics school texts from the perspective of readability and use of specific terms. The study uses the survival function to associate the readability of physics school text to the length of terms used in the text. First, the study compares the survival functions of two full texts and that of the terms in these texts, and then analyzes the associated relative readability. Next, the results of two cloze tests involving 150 students are compared. The last step investigates the randomness of the differences between the results. The results show a strong correlation between the test scores and the probability distributions of terms used in the school texts. The difference between the probability distribution of the compared texts corresponds with the differences between the appropriate survival functions, where random fluctuations in the frequency of terms are suppressed.
\end{abstract}

UDC Classification: 37.02; DOI: http://dx.doi.org/10.12955/cbup.v5.1031

Keywords: Cloze test, Survival function, readability, physics school text

\section{Introduction}

Because of fewer classes today than previously, current physics students need greater access to textbooks than ever for learning to remain effective. Thus, for effective study with fewer classes more emphasis is placed on home study. As a result, students need materials free of errors. In the time of the internet, information is easily accessible. However, finding appropriate information, especially in readable text form, is problematic. The readability of school texts is the first and foremost precondition for a valid study hour.

In accordance with Škorecová et al. (2016b), terms are part of physics school texts, and we cannot write school text without terms. Thus, the frequency of terms is critical for a readability study. However, the length of such is also important (Škorecová, et al., 2016a). In this case, where the frequency of terms is similar between texts, the most readable and thus more suitable for study hour relates to the frequency counts and length of the terms.

The aim of this study was to compare two physics school texts from the perspective of readability and use of specific terms.

\section{Data and Methodology}

This study examined the following texts:

- Physics for $2^{\text {nd }}$ grade on high school (2r) by Demkanin (2010), Section: Properties of Liquid and Gases

- Physics for $3^{\text {rd }}$ grade on high school (3r) by Pecho (1994), Section: Stationary and NonStationary Magnetic Field

The hypothesis was that the readability of physics school text depends on the length of the terms.

The study also examined the importance of theoretical knowledge as part of the learning process, considering terms as the basic building elements of such knowledge. Terms were separated from both texts, prior to calculating the survival function for the terms.

Two cloze tests were used to confirm or reject the above hypothesis $\left(\mathrm{H}_{\mathrm{A}}\right)$. The first involved the text $2 \mathrm{r}$ and the second the text 3 r. Both tests examined 300 words with every 7 th word missed. A total of 150 students of a high school in Nitra performed the two tests before studying this topic.

Finally, the study findings were validated regarding the significance of differences in the survival function and the cloze tests. The null hypothesis $\left(\mathrm{H}_{0}\right)$ was that the difference between the survival functions for terms of the different school books was random. For this, the $p$-value for chi-square $\left(\chi^{2}\right)$ distribution was calculated using the Monte Carlo method to generate data (Meunier et al., 2001).

\footnotetext{
${ }^{1}$ Department of Physics, Constantine the Philosopher University in Nitra, ivana.skorecova@ukf.sk

${ }^{2}$ Department of Physics, Constantine the Philosopher University in Nitra, ateleki@ukf.sk

${ }^{3}$ Department of Physics, Constantine the Philosopher University in Nitra, lzelenicky@ukf.sk
} 


\section{Survival Function in Study of Readability}

The required information was encoded in the probability distribution function (PDF) of words of a given length (Škorecová et al., 2016a). However, in the case of terms, the appropriate PDF was found to be unsuitable due to the relatively small number of terms. The fluctuation in the PDF was significant where the analyzed text was short. For this reason, the study used the cumulative distribution function (CDF) instead of the PDF. In the CDF, the fluctuations were suppressed due to its random characteristic. The survival function (SF), or complementary CDF, has the same property as CDF. Here, the survival function of probabilities was used to obtain a decreasing function. The survival function $S_{n}$ was defined as follows:

$$
S_{n}=\sum_{j=n}^{\infty} p_{j}, \quad n=1,2,3, \ldots, \text { and } S_{1}=1,
$$

where $p_{j}$ was the frequency of words in the analyzed text. The infinite sum was formal only, as all texts contain a word with a maximal length. The survival function, $S_{n}$ for words, yielded better results and improved graphical visualization of the results. The readability of the simultaneous comparison of the three texts in graphs was improved using this approach.

\section{Results and Discussion}

Despite the improvements mentioned above, little differences in readability were evident between the texts, 2r (Demkanin, 2010) and 3r (Pecho, 1994) (Figure 1). The finer scale of Figure 2 displays the difference between the survival functions of the analyzed pair of tests. In this difference, the fluctuation was naturally suppressed.

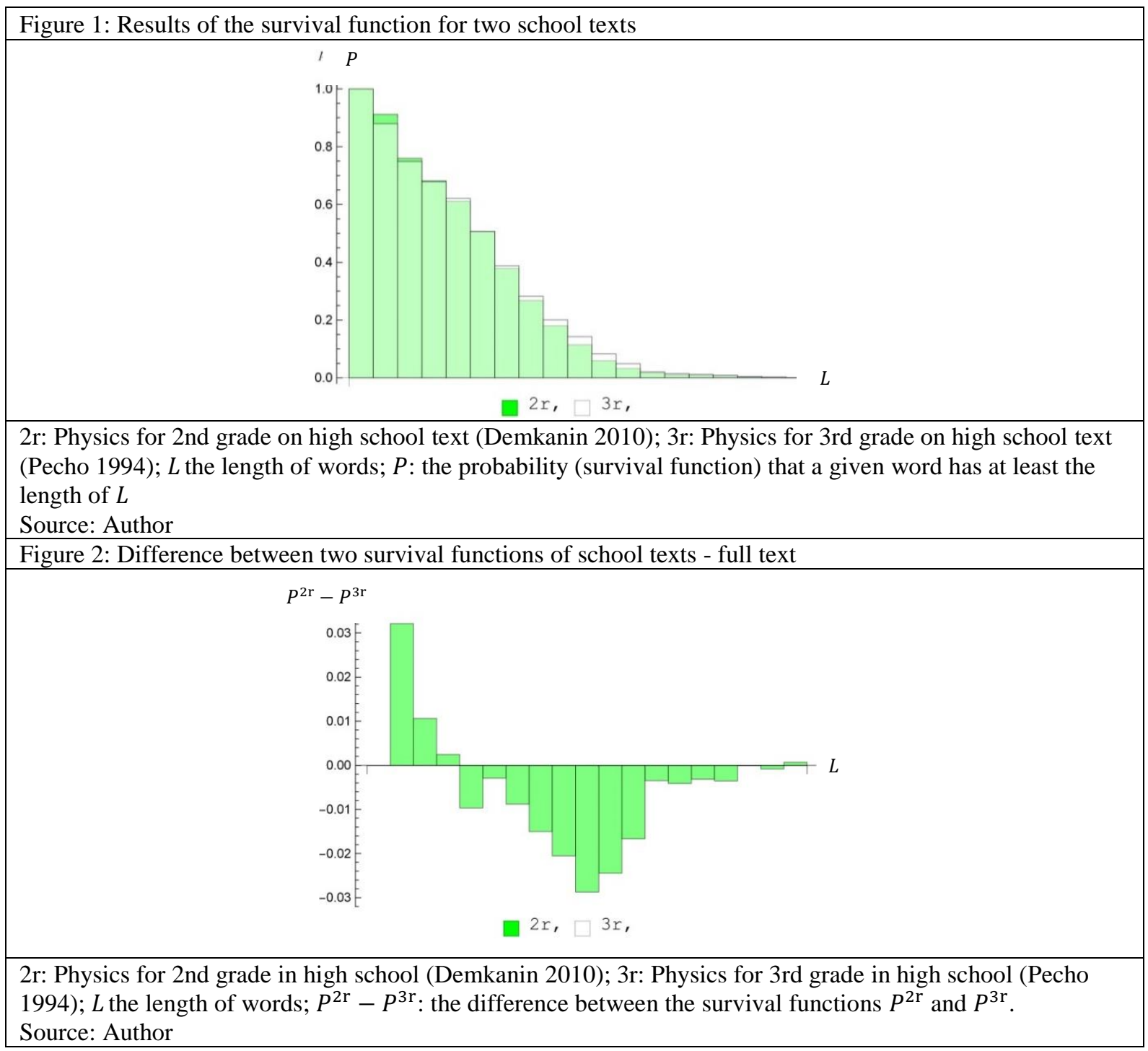


Table 1 presents characteristics of the analyzed texts. Because of different topics, authors used distinctive terms with discrete lengths. Whereas Figures 1 and 2 show the readability of texts as somewhat similar, Figures 3 and 4 reveal differences in respect of terms. Thus, text $3 \mathrm{r}$ was less readable than text $2 \mathrm{r}$ (see Figure 5).

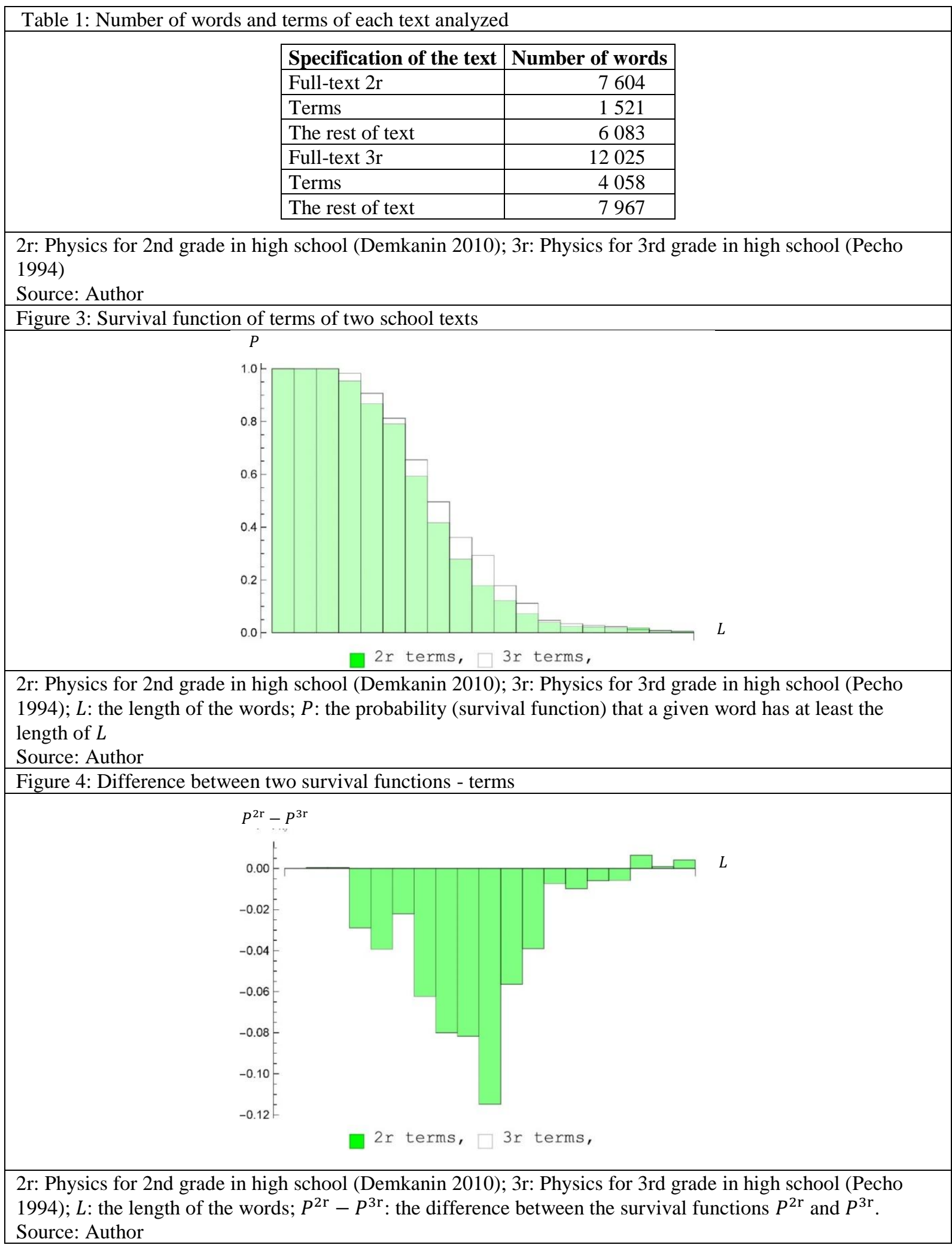

We compared the success of students in two cloze test, the first close test for the textbook $2 \mathrm{r}$ (Demkanin 2010) and the second close test for the textbook 3r (Pecho 1994). The null hypotheses was that there was no difference. Figures 3 and 4 indicate that text $3 \mathrm{r}$ was the less readable of the two texts. 
Table 2 shows the level of significance for a result of null hypotheses. Figure 5 presents the success of students in the cloze tests.

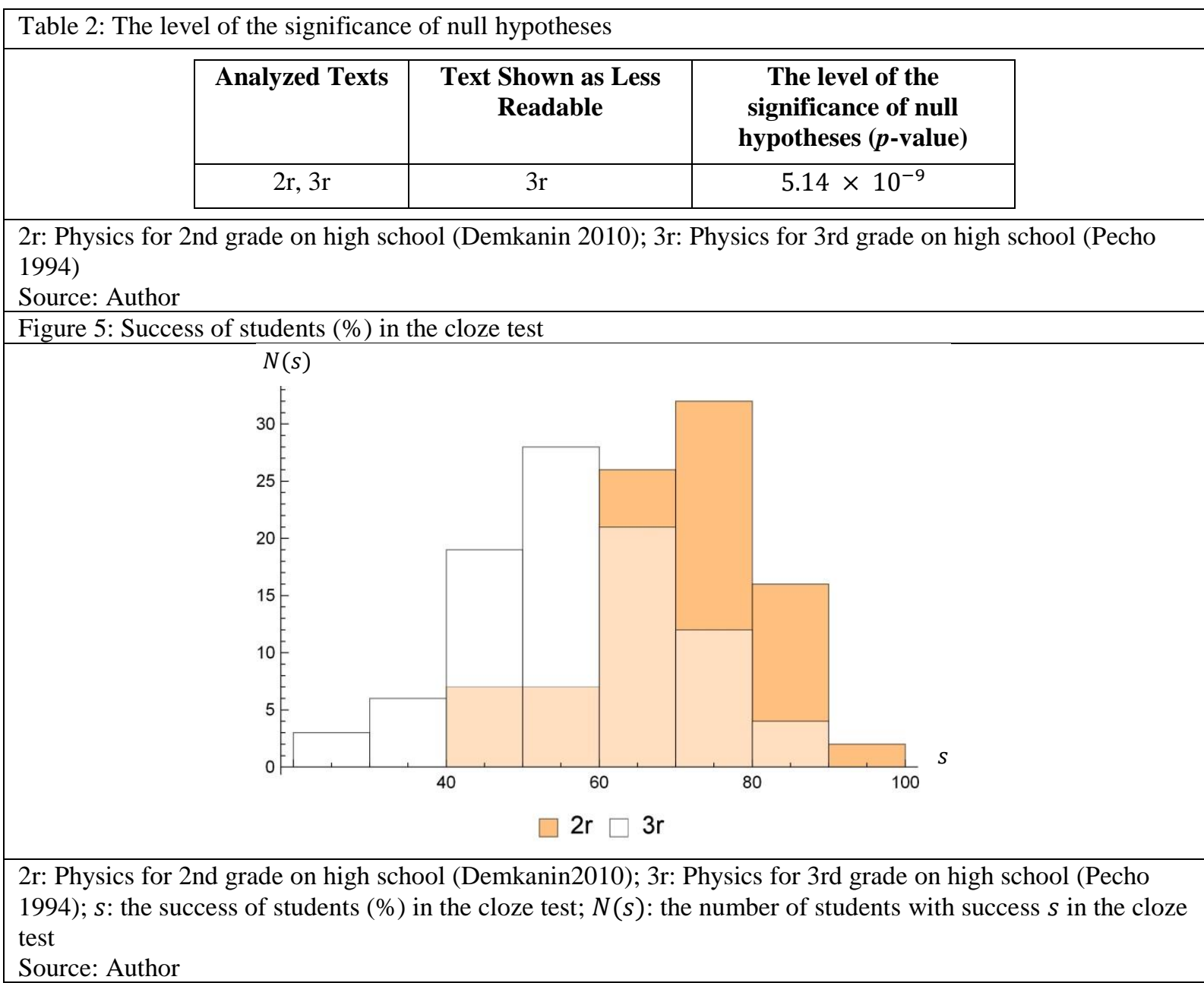

Figure 6: The $\chi^{2}$ distribution calculated from Monte Carlo (MC) generated data with the red line showing the
approximation of the $X^{2}$ distribution defined in (Škorecová et al., 2016a) which is more suitable for practical
purposes.
2r: Physics for 2nd grade on high school (Demkanin2010); 3r: Physics for 3rd grade on high school (Pecho
1994); $X^{2}:$ the quantity defined in (Škorecova 2016a) by Eq. (2) has a distribution similar to the $\chi^{2}$
distribution; $p$ : the probability distribution (PDF)
Source: Author




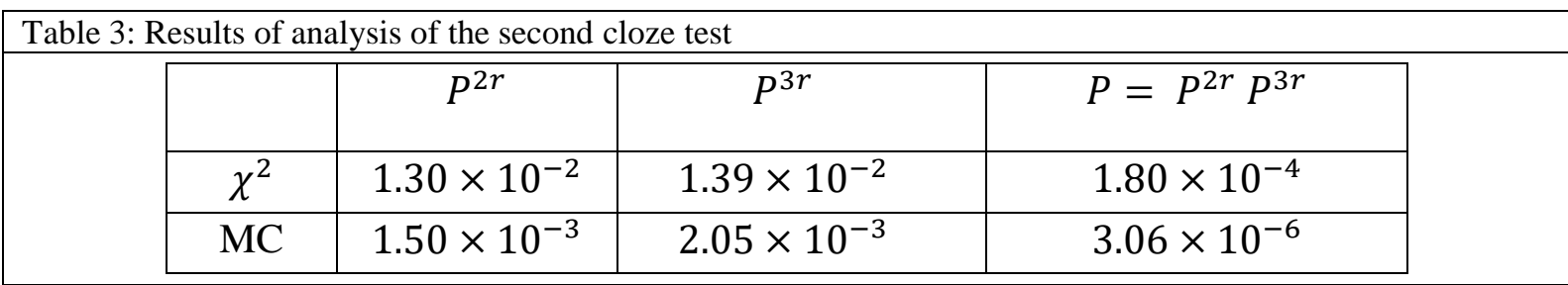

MC: Monte Carlo method; P: Level of significance; 2r: Physics for 2nd grade on high school (Demkanin 2010); 3r: Physics for 3rd grade on high school (Pecho 1994)

Source: Author

The results validated the hypothesis that text with shorter terms performed better in the cloze test. Thus, school texts with shorter terms are deemed more readable than texts with longer terms. Therefore, readability of school texts depends on the length of terms.

To compare the similarity of the two textbooks, we used the statistical quantity $X^{2}$ defined in (Škorecová et al., 2016a). This quantity has a similar probability distribution as the well known $\chi^{2}$ distribution does.

Figure 6 and Table 3 show the results of the $\chi^{2}$ distribution using the Monte Carlo method. The results confirmed the null hypothesis $\left(H_{0}\right)$ that the difference between the survival functions of terms of the school books was random $\left(p=1.80 \times 10^{-4}\right)$.

\section{Conclusion}

The readability of school texts is a crucial parameter for effective learning. Such readability depends on the frequency of terms. For evaluating school texts, an alternative to using the cloze test is to use the survival function of terms to compare texts. The results of this study show that this type of analysis is useful and can provide teachers with results faster than if they were to use the cloze test alone. By using more readable texts, the studying of texts will be more effective, especially for home study.

\section{References}

Demkanin, P. (2016) in Physics education in Slovakia, intended, implemented and achieved curriculum - higher secondary education, in: Vymedzenie obsahu školskej fyziky Nitra: UKF, 2016. - S. 44-50 ISBN 978-80-558-1080-5, book of paper of DIDFYZ 2014: medzinárodná konferencia - Račkova dolina, 15.-18.10.2014. SK

Demkanin, P., Horváth, P., Markovičová, Z., Chalipová, S. (2010) Physics for 2nd grade on high school, Patria I., spol. s.r.o., Prievidza

Meunier, M, Ancey, C., Naaim, M. (2001), Statistical probability predetermination of avalanche runout altitudes using a combination of deterministic model and well-documented database (Mise au point d'une méthode de prédétermination statistique des cotes d'arrêt d'avalanches), Houille Blanche, number 6-7, Scopus

Pecho, A., Lepil, O., Houdek, V. (1994) Physics for 3rd grade on high school, Number 2, svornost', spol. s.r.o.

Škorecová, I., Teleki, A., Lacsný, B., Zelenický, L. (2016a). An easy to compare tool for more readable (Physics) textbooks, Physics Education, Volume 51, number 6, Scopus

Škorecová, I., Teleki, A., Zelenický, L. (2016b). Should we include terms in readability formulas of Slavonic texts? In proceedings: CBU International Conference on Innovationis in Science and Education, March 23-25, 2016, Prague, Accepted paper 